\title{
Valoração econômica de uma unidade de conservação urbana, Cuiabá, Mato Grosso
}

Economic valuation of a unit conservation urban, Cuiabá, Mato Grosso

L'évaluation économique d'une unité de conservation urbain, Cuiabá, Mato Grosso

Valoración económica de una unidad de conservación urbana, Cuiabá, Mato Grosso

\author{
Stéphanie Thayssa Mattos Fontes Nascimento* \\ Edilene Silva Ribeiro** \\ Roberto Antônio Ticle de Melo e Sousa***
}

Recebido em 10/4/2011; revisado e aprovado em 29/8/2011; aceito em 10/3/2012

\begin{abstract}
Resumo: Este trabalho tem como objetivo expressar o valor de uso recreacional do Parque Estadual Mãe Bonifácia (PEMB), utilizando-se os métodos de Valoração Contingente e o método do Custo de Viagem. O estudo foi desenvolvido no perímetro urbano de Cuiabá, com os dados coletados através de questionários em entrevistas feitas aleatoriamente junto aos usuários do Parque.

Palavras-chave: Custo de viagem. Valoração contingente. Valoração econômica ambiental.

Abstract: This paper aims to express the value of recreational use of the State Park Mãe Bonifácia (PEMB), using the methods of Contingent Valuation and Travel Cost Method. The study was conducted in the urban area of Cuiabá, with data collected through questionnaires in random interviews with users of the park.

Key words: Cost of travel. Contingent valuation. Economic valuation environment.

Résumé: Cet article vise à exprimer la valeur de l'usage récréatif de la State Park Mãe Bonifacia (PEMB), en utilisant les méthodes d'évaluation contingente et la méthode du coût du trajet. L'étude a été menée dans la zone urbaine de Cuiabá, avec les données recueillies au moyen de questionnaires à des entrevues au hasard avec les utilisateurs du parc.

Mots-clés: Coûts de déplacement. De l'évaluation contingente. De l'environnement l'évaluation économique.

Resumen: El presente documento tiene por objeto expresar el valor de uso recreativo de la Mãe Bonifacia Estado Parque (PEMB), utilizando los métodos de valoración contingente y el método del coste del viaje. El estudio se llevó a cabo en el área urbana de Cuiabá, con datos recogidos a través de cuestionarios en las entrevistas al azar con los usuarios del parque.

Palabras clave: Gastos de viaje. Valoración contingente. El medio ambiente valoración económica.
\end{abstract}

\section{Introdução}

O acelerado crescimento urbano, a consequente alteração da paisagem e das características ambientais, principalmente nas grandes cidades, têm gerado uma série de problemas que se relacionam diretamente com a qualidade ambiental e a qualidade de vida de suas populações.

A manutenção do verde vem sendo justificada pelo seu potencial em realçar aspectos associados à qualidade ambiental enquanto provedora de benefícios ao homem, interferindo positivamente na qualidade de vida pela manutenção das funções ambientais, sociais e estéticas, amenizando as propriedades negativas do processo de urbanização.

A valoração monetária desses benefícios busca subsidiar a tomada de decisão do poder público e da sociedade civil sobre o gerenciamento dos recursos naturais e propicia a realização de uma análise social de custo-benefício para reservas naturais.

O Brasil tem cerca de 3,9\% do seu território sob a proteção federal na forma de Unidades de Conservação em diferentes categorias, distribuídos em 35 Parques Nacionais, 23 Reservas Biológicas, 21 Estações Ecológicas, 16 Áreas de Proteção Ambiental, 9 Reservas Extrativistas e 39 Florestas Nacio-

\footnotetext{
* Graduação em Engenharia Florestal - Departamento de Engenharia Florestal FENF, Universidade Federal de Mato Grosso. E-mail: stephaniethayssa@hotmail.com.br

** Programa de Pós-graduação em Ciências Florestais e Ambientais PPGCFA, Universidade Federal de Mato Grosso. E-mails: eng.edilene@gmail.com.br, robertasantoz@gmail.com.br

*** Prof. Dr. Graduação e Pós-graduação do Departamento de Engenharia Florestal FENF/PPGCFA, Universidade Federal de Mato Grosso. E-mails: ratms@terra.com.br, pasamc@brturbo.com.br.
} 
nais que, em sua maioria, estão carentes de recursos para uma manutenção adequada (ABREU, 2004).

Segundo Brasil (2000), os parques nacionais, estaduais e municipais são concebidos como unidades de conservação de proteção integral, que têm como objetivo principal a conservação da natureza, o que inclui pesquisas científicas, atividades de educação e interpretação ambiental, recreação e turismo ecológico, desenvolvidas de acordo com as normas estabelecidas em seu plano de manejo.

De acordo com Cunha e Menezes (2005), as Unidades de Conservação Urbanas apresentam maior vulnerabilidade em relação às áreas protegidas mais remotas. Primeiramente, em relação aos impactos decorrentes do processo de urbanização, devido a dimensões reduzidas, pressão humana, introdução de espécies exóticas, contaminação dos mananciais, e raramente têm prioridade dentro das políticas públicas de conservação da natureza.

A conservação da biodiversidade e o provimento de recursos naturais permitem que cientistas, educadores e a comunidade em geral encontrem material para suas pesquisas e satisfação de diversas necessidades, mesmo que muitos desses bens e serviços oferecidos por uma Unidade de Conservação não tenham valor de mercado (ABREU, 2004). Muitos dos benefícios das áreas protegidas são difíceis de ser medidos em termos monetários, fazendo-se necessário o uso de métodos de valoração econômica.

A importância da economia ambiental tem crescido muito nas últimas décadas. Esse fato reflete a crescente preocupação mundial com relação à perda de biodiversidade e a ideia de que o homem tem responsabilidade moral de cuidar da natureza.

Devido ao possível esgotamento dos recursos naturais, surgiram vários estudos buscando o manejo e a conservação do meio ambiente, utilizando, para isso, diversas metodologias que visam levantar o valor intrínseco dos bens e serviços ambientais, expressas por meio dos processos de valoração econômica.

A maioria dos bens e serviços ambientais (parques, locais para recreação e outros recursos naturais públicos ou privados de uso coletivo) e das funções providas ao homem pelo ambiente não é transacionada pelo mercado. Pode-se, ponderar que a necessidade de estimar valores para os ativos ambientais atende às necessidades da adoção de medidas que visem à utilização sustentável do recurso (ROMEIRO et al., 1996).

Qualquer que seja a forma de gestão a ser desenvolvida por governos, organizações não governamentais, empresas ou mesmo famílias, o gestor terá que equacionar o problema de alocar um orçamento financeiro limitado frente a inúmeras opções de gastos que visam diferentes opções de investimentos ou de consumo.

O valor econômico dos recursos ambientais geralmente não é observável no mercado através de preços que reflitam seu custo de oportunidade.

Os métodos de valoração econômica buscam estimar um valor para o recurso ambiental fora da forma monetária convencional. Mais especificamente, busca-se mensurar as preferências individuais das pessoas por um recurso ou serviço ambiental, ou seja, não é o ativo ambiental que recebe um "valor", e sim as preferências das pessoas, quando ocorre mudança na qualidade ou quantidade do recurso ambiental. De outra maneira, pode-se dizer que o valor econômico do ativo natural é aferido a partir da observação de seus atributos pelos indivíduos (ABREU et al., 2008).

A valoração econômica ambiental é uma ferramenta fundamental para a formulação e a avaliação de políticas públicas orientadas ao desenvolvimento sustentável e à preservação dos recursos ambientais. As técnicas de valoração econômica buscam medir as preferências das pessoas por um recurso ou serviço ambiental e, portanto, o que está recebendo "valor" não é o meio ambiente ou o recurso, mas as preferências das pessoas em relação a mudanças de qualidade ou quantidade ofertada do recurso ambiental (MAY et al., 2003).

De acordo com Nogueira e Medeiros (1998), de uma maneira geral, os métodos de valoração econômica ambiental são utilizados para estimar os valores que as pessoas atribuem aos recursos ambientais, com base em suas preferências individuais.

A atual literatura econômica do meio ambiente distingue três tipos de valores 
que compõem o valor econômico total do ambiente: valor de uso (direto e indireto), valor de opção e valor de existência, os dois últimos não serão abordados neste trabalho. Valor de opção reflete a disposição a pagar para garantir a disponibilidade futura de um recurso ambiental (uso futuro), valor de existência retira o caráter utilitarista da valoração, pois considera que um indivíduo mesmo não consumindo determinado bem ou serviço ambiental, está disposto a pagar pela sua preservação ou conservação (ROMEIRO et al., 1996).

Entre os principais métodos de valoração ambiental, temos o Custo de viagem (MCV), Preços Hedônicos, Custos de Reposição, Gastos Defensivos, Dose Resposta, e Método de Valoração Contingente (MVC). Os métodos são classificados de várias maneiras por diferentes autores e geralmente são ditos diretos e indiretos. Os métodos de valoração indiretos (p.ex. MCV) são aqueles que inferem sobre o valor econômico do recurso ambiental a partir da observação da preferência revelada do indivíduo em mercados correlacionados ao ativo ambiental. Os métodos são ditos diretos (p.ex. MVC) quando procuram inferir sobre as preferências dos indivíduos por bens ou serviços ambientais a partir de perguntas feitas diretamente às pessoas (MAY et al., 2003).

A maioria dos recursos naturais não tem seu preço definido dentro de um mercado tradicional. A teoria da valoração econômica ambiental propõe que o valor do recurso ambiental seja mensurado pelos seus atributos associados ao uso ou não desse recurso (ABREU et al., 2008).

Este trabalho tem como objetivo estimar os valores de uso recreacional do Parque Estadual Mãe Bonifácia, utilizando-se os métodos de Valoração Contingente e do Custo de Viagem e, através destes, analisar o perfil socioeconômico dos frequentadores.

\section{Material e métodos}

Neste trabalho, optou-se por empregar o Método de Custo de Viagem (MCV) e o Método Valoração Contingente (MVC) para estimar o valor do uso recreacional do Parque Estadual Mãe Bonifácia.

\section{A área de estudo}

O Parque Estadual Mãe Bonifácia está localizado no perímetro urbano do município de Cuiabá, Mato Grosso, entre as coordenadas geográficas $15^{\circ} 34^{\prime} 44^{\prime \prime} \mathrm{S}$ e $56^{\circ} 05^{\prime} 16^{\prime \prime} \mathrm{W}$, com 77,16 hectares de área total, tendo como limites as Avenidas Miguel Sutil, Senador Filinto Muller e Rua Corsino do Amarante. A área do parque foi, primeiramente, transformada em Unidade de Conservação de Interesse Local pela Lei Complementar de Gerenciamento Urbano n. 004, de 24 de dezembro de 1992 (CUIABÁ, 1992). Posteriormente, o Governo do Estado transformou-a em Parque Estadual pelo Decreto de n. 1.470, de 09 de junho de 2000 (MATO GROSSO, 2000).

O Parque tem excelente estrutura para atendimento ao público e abriga a Superintendência de Educação Ambiental (SUEA) ligada à Secretaria de Estado do Meio Ambiente (SEMA). A SUEA é responsável por garantir atividades de educação ambiental nas áreas e por administrar os parques estaduais urbanos, os quais podem ser visitados diariamente das 6 às 18 horas, sem que se cobre taxa de visitação.

Além das belezas naturais, o parque conta com infraestrutura como mirante, trilhas pavimentadas e de areia, trilhas para observação da fauna e flora silvestre, aparelhagem para exercícios físicos, aulas gratuitas de aeróbica, acompanhamento de profissionais da medicina preventiva, parque infantil, praças, estacionamentos, sanitários, bebedouros e concha acústica (Figura 1). 


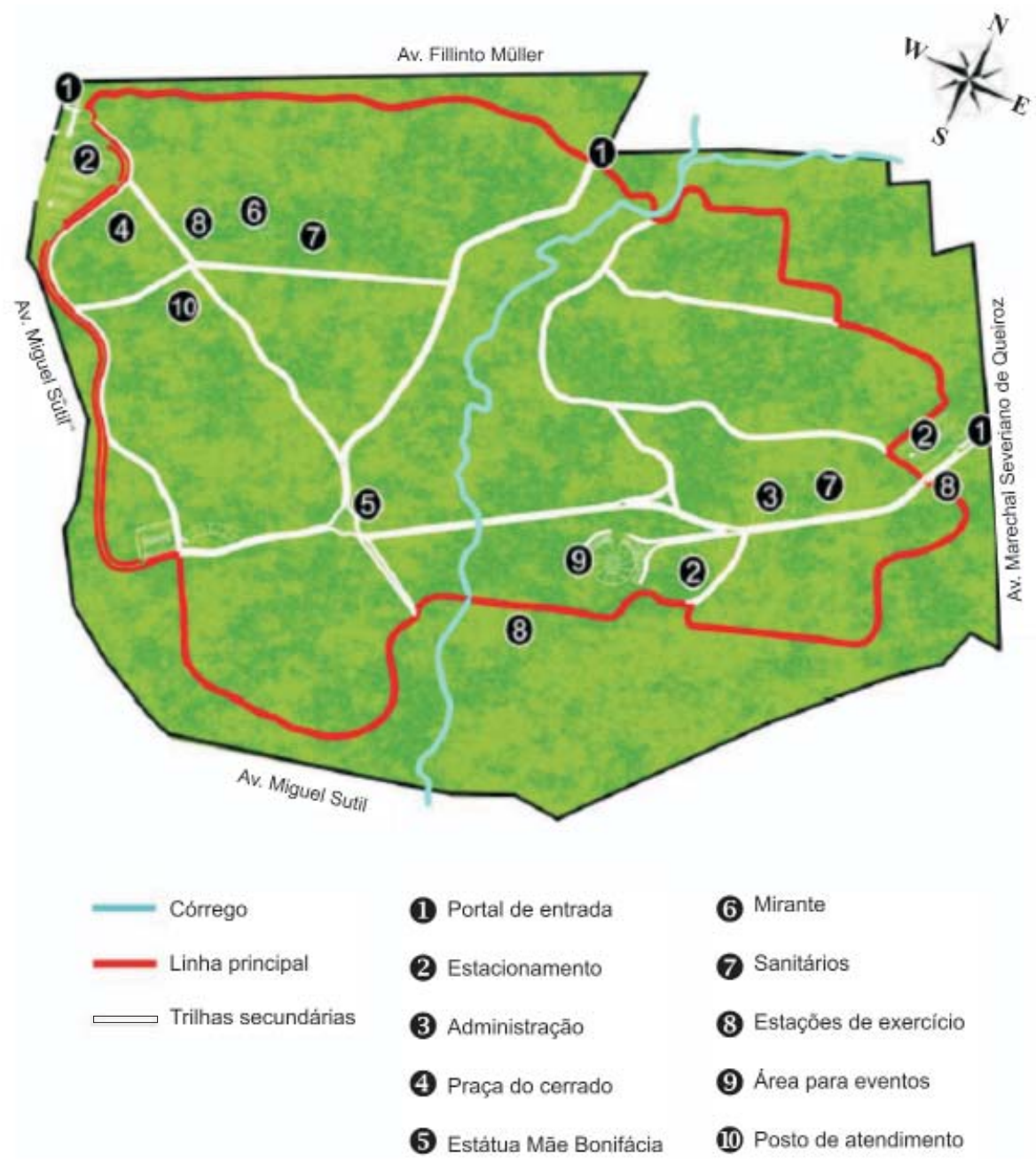

Figura 1 - Croqui do parque da cidade Mãe Bonifácia, Cuiabá, MT. Fonte: Ângela M. Santana e Flávia M. M. Moura

\section{A coleta de dados}

Para levantamento dos dados deste trabalho, utilizou-se da aplicação aleatória de questionários individualmente a cada visitante nos portões do Parque Mãe Bonifácia, sob forma de entrevista.

A entrevista estruturada é uma técnica de produção de dados, que se baseia na utilização de um questionário como instrumento de coleta de dados. Considera-se que a técnica de entrevistas estruturadas permite a comparabilidade entre as respostas. Ela baseia-se em uma estrutura uniforme, enquanto um número calculado de pessoas é entrevistado de modo que seja considerada uma amostra estaticamente representativa da população para propósitos de generalização (MAY, 2004).

Entre as principais vantagens das entrevistas estruturadas estão os custos relativa- mente baixos e a possibilidade de análise estatística dos dados, já que as respostas obtidas são padronizadas (GIL, 2007).

O procedimento empregado na pesquisa de campo, tanto para aplicação do método de valor contingente como para o método do custo de viagem, constou de aplicação de questionários sob forma de entrevista, com posterior tabulação e análise dos dados. Os questionários utilizados são classificados como fechados, em que se pede para o entrevistado escolher uma alternativa numa lista apresentada.

O questionário utilizado buscou levantar informações do entrevistado como sexo, idade, estado civil, grau de escolaridade, profissão, local de procedência; renda mensal; maneira de deslocamento até o parque, o meio de transporte utilizado, o tempo de deslocamento, o objetivo da visita ao parque, 
frequência de visita, tempo de permanência no parque, a disposição a pagar em termos de valores, por cada visita ao parque, entre outros.

Foi aplicado um total de 100 questionários aleatoriamente, nos finais de semana (sábados e domingos), no período de 23/8/09 a 10/10/09 com a finalidade de levantar o perfil dos entrevistados, suas características socioeconômicas, informações para aplicação do método de valoração de custo de viagem e do método de valoração contingente.

Para efeito de melhor entendimento da região de estudo, fez-se uma estimativa do número total de visitantes diários ao parque nos finais de semana (sábados, domingos e feriados). Essa estimativa constou de nove amostragens diárias, cada uma de uma hora, distribuídas em diferentes horários do dia, em diferentes dias dentro do período considerado.

\section{O Método de Custo de Viagem (MCV)}

Para usar os serviços recreativos do parque, os indivíduos têm de se deslocar dos diferentes pontos de origem da cidade até esse local de recreação. Os custos envolvidos nesse deslocamento são parte significativa do preço pago pelo indivíduo para visitar o local. Através do questionário, procura-se identificar os gastos feitos pelos entrevistados para se deslocar até o parque, identificando os diferentes meios de locomoção.

A lógica por trás desse método é que, quando o recurso ambiental é utilizado para atividades recreativas, tal como em parques, estes geram um fluxo de serviços mensuráveis para os indivíduos. Cada visita ao lugar de recreação envolve uma transação implícita, na qual o custo total de viajar a esse lugar é o preço que se paga para utilização dos serviços recreativos do parque.

Quanto mais longe do parque os visitantes vivem, menos uso do parque (menor número de visitas) é esperado que ocorra, uma vez que se aumenta o custo de viagem para visitação. Aqueles que vivem mais próximos ao parque tenderão a usá-lo mais (maior número de visitas), na medida em que o preço implícito de utilizá-lo (o custo de viagem) será menor.

\section{O Método de Valoração Contingente (MVC)}

Segundo o Manual para Valoração Econômica de Recursos Ambientais elaborado pelo Ministério do Meio Ambiente (MMA, 2002), citado por Souza (2007), descrevem-se os estágios para a aplicação do MVC da forma como se segue: no primeiro estágio, define-se a pesquisa (cenário) e prepara-se o questionário; no segundo estágio, realiza-se a pesquisa piloto e pesquisa de campo final; finalmente estima-se a DAP média no cálculo da medida monetária e na agregação de resultados, podendo ou não multiplicar pela população alvo da pesquisa.

O questionário para levantamento da DAP no MVC submete o entrevistado a opções dentro de uma lista de diferentes intervalos de valores de taxa de admissão ao parque (valor da entrada).

\section{Resultados e discussões}

O Parque Estadual Mãe Bonifácia funciona das 06 horas da manhã às 18 horas sem interrupção, não sendo cobrada taxa de visitação. Através dos dados amostrais de frequência do parque, estimou-se que o número de visitantes é de cerca 2.226 visitantes por dia por final de semana, no período em que os questionários foram aplicados.

\section{Perfil socioeconômico dos entrevistados}

Entre os entrevistados do parque, 59\% são moradores da região oeste da cidade de Cuiabá e se deslocam a uma distância média de seis quilômetros (ida e volta) para a visita ao parque. Os entrevistados situados na região leste da cidade que respondem por $15 \%$ das visitas, deslocam-se (ida e volta) a uma distância média de dez quilômetros/visita. Os da região norte, com $11 \%$, deslocam-se a uma distância média de (dezoito) $18 \mathrm{~km}$, os $5 \%$ da região sul se deslocando a uma distância média de (vinte) 20 km, e 10\% são moradores do município de Várzea Grande, que se deslocam a uma distância média de (dezesseis) $16 \mathrm{~km}$ (Figura 2).

Esses resultados encontrados, de relação inversa entre percentual de visitantes e distância média do local de sua procedência, 
são semelhantes ao encontrado em outros estudos. Como por exemplo, no levantamento realizado no Parque Ingá na cidade de Maringá, $\mathrm{PR}$, onde $52 \%$ dos usuários eram moradores de bairros circunvizinhos, e no Parque Florestal da cidade de Sinop, MT, onde 73\% dos frequentadores são residentes nas proximidades do Parque (VILANOVA, 2008).

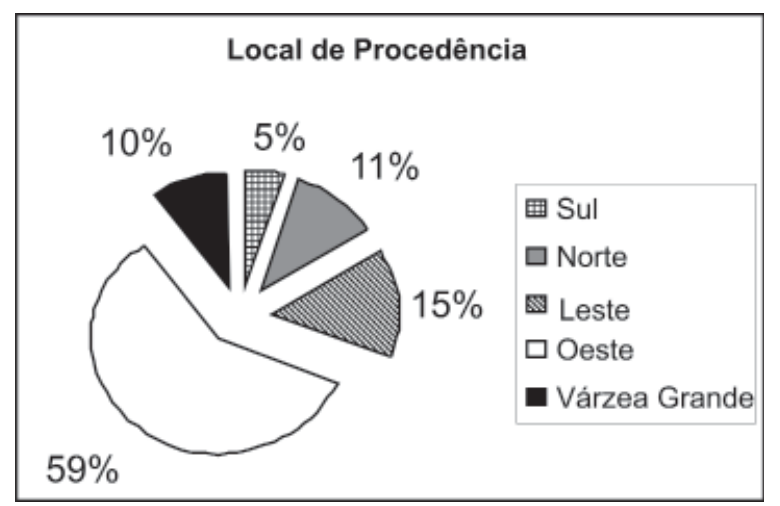

Figura 2 - Local de procedência dos entrevistados do Parque Estadual Mãe Bonifácia, Cuiabá, MT. 2009.

Entre os 100 frequentadores entrevistados, ambos os sexos frequentam o parque quase que igualmente, $55 \%$ dos entrevistados são do sexo masculino e $45 \%$ do sexo feminino. Para Koga et al. (2011), a diferença entre os entrevistados foi de 50,71 do sexo masculino e 47,72 do sexo feminino, também demonstrando diferença mínima entre os frequentadores dos parques estaduais.

A faixa etária dos frequentadores entrevistados do parque apresentou os seguintes resultados: $2 \%$ deles se situam na faixa etária entre 11 e 20 anos, $19 \%$ na faixa etária entre 21 e 30 anos, $26 \%$ entre 31 e 40 anos; $17 \%$ entre 41 e 50 anos, $22 \%$ entre 51 e 60 anos e $14 \%$ com mais de 60 anos (Figura 3). Já no trabalho realizado por Koga et al. (2011), em trilhas nos parques estaduais de São Paulo, a faixa etária entre 14 e 20 anos compôs 16,07\%; 21 e 30 anos, 34,34\%; 31 e 40 anos 23,50\%; e acima de 40 anos, 22,30\%.

Os dados obtidos indicam uma pequena diferença dos resultados adquiridos nos trabalhos realizados no parque estadual (PE) do Ibitipoca, Minas Gerais (LADEIRA et al., 2007), os quais apuraram que a maioria dos visitantes tinha entre 20 e 29 anos (41,4\%); no parque municipal (PM) Chico Mendes, onde foi observada a presença de jovens entre $15 \mathrm{e}$
30 anos (70\%) (SILVA et al., 2010); e na Floresta Nacional (FLONA) de Ipanema, os jovens até 30 anos também são a maioria dos visitantes (SOUZA; MARTOS, 2008).

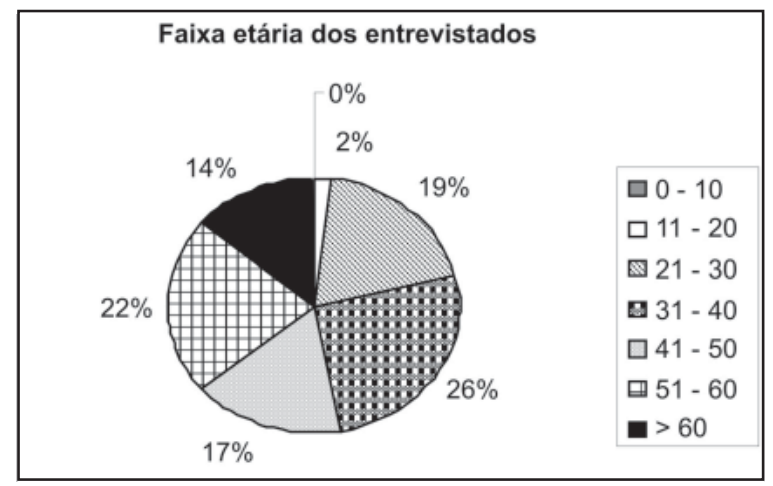

Figura 3 - Faixa etária dos entrevistados no Parque Estadual Mãe Bonifácia, Cuiabá, MT. 2009.

A grande maioria das pessoas que frequentam o parque são pessoas casadas 58\%, $20 \%$ de solteiros, $12 \%$ divorciados e viúvos $8 \%$.

Com relação à renda familiar, foram consideradas seis categorias, sendo $15 \%$ com renda mensal acima de $\mathrm{R} \$ 4.000,00 ; 27 \%$ dos entrevistados têm renda mensal entre $\mathrm{R} \$$ $3.000,00$ e $\mathrm{R} \$ 4.000,00 ; 23 \%$ entre $\mathrm{R} \$ 2.000,00$ e $R \$ 3.000,00,22 \%$ entre $R \$ 1.000,00$ e $R \$$ $2.000,00,10 \%$ entre $R \$ 500,00$ e $1.000,00$ e 3\% com renda inferior a $\mathrm{R} \$ 500,00$. Confirmando os resultados Malta e Costa (2009), em sua pesquisa no parque nacional da Tijuca, encontraram que $31,58 \%$ dos entrevistados recebem acima de 10 salários mínimos, seguidos de $35,97 \%$ recebendo até quatro salários, algo em torno de 2.400 reais.

Tabela 1 - Nível de escolaridade dos entrevistados do Parque Estadual Mãe Bonifácia, Cuiabá, MT, 2009.

\begin{tabular}{l|c}
\hline Nível de escolaridade & Número de pessoas \\
\hline Analfabeto & 0 \\
Alfabetizado & 1 \\
Ensino Fundamental & 1 \\
Ensino Médio & 24 \\
Ensino Superior & 73 \\
Outros & 1 \\
\hline
\end{tabular}

De acordo com os resultados (Tabela 1), considerando-se seis categorias de educação formal, observou se que $73 \%$ dos entrevista- 
dos possuem ensino superior completo dos quais $81 \%$ está na ativa e $19 \%$ são aposentados. Em estudos realizados por Hildebrand et al. (2002), no Bosque Alemão em Curitiba, foram encontrados percentuais semelhantes, $43,2 \%$ nível superior completo, $22,1 \%$ superior incompleto, 29,5\% secundário e apenas 5,3 com o nível primário. Nos estudos realizados no parque municipal Barigui em Curitiba, PR, a maioria dos frequentadores possuem nível superior, cerca de, 56,75\% (SOUZA, 2010).

Tabela 2 - Frequência dos entrevistados do Parque Estadual Mãe Bonifácia, Cuiabá, MT, 2009.

\begin{tabular}{l|c}
\hline \multicolumn{1}{c|}{ Frequência } & Número de pessoas \\
\hline Diariamente & 18 \\
Uma vez por semana & 24 \\
Duas vezes por semana & 19 \\
Esporadicamente & 39 \\
Outros & 0 \\
\hline
\end{tabular}

Pela tabela 2, pode-se observar que $39 \%$ dos entrevistados frequentam o parque esporadicamente, $24 \%$ uma vez por semana, $19 \%$ frequentam duas vezes por semana e apenas $18 \%$ dos entrevistados frequentam o parque diariamente.

Quanto ao tempo de permanência por visita ao parque, $24 \%$ dos entrevistados costumam permanecer até uma hora no parque, $67 \%$ de uma a duas horas, e $9 \%$ permanecem no parque por mais de duas horas.

A maioria dos entrevistados prefere visitar o parque nos finais de semana, sendo que $42 \%$ frequentam aos sábados e domingos, $23 \%$ somente aos sábados, $17 \%$ somente aos domingos e $18 \%$ diariamente.

Quanto ao período do dia de preferência em que os entrevistados frequentam o parque, $79 \%$ preferem o período matutino, $15 \%$ o vespertino e $6 \%$ frequentam o parque em ambos os períodos.

Com relação ao item segurança, 79\% dos frequentadores entrevistados sentem-se seguros enquanto realizam atividades no parque, $21 \%$ não se sentem seguros, sendo que $57 \%$ dos entrevistados já souberam da ocorrência de assalto no parque, e $43 \%$ nunca souberam de nenhum assalto ocorrido no parque.
Quanto à finalidade de utilização do parque pelos entrevistados, $37 \%$ fazem caminhadas, $19 \%$ frequentam para passear, $1 \%$ para leitura e $12 \%$ em atividades mistas.

\section{Valorização de custo de viagem}

Neste método foram observados quais os meios de transportes que as pessoas utilizam para o deslocamento até ao parque para que se possa calcular qual a disposição a pagar (DAP) para o entrevistado que se desloca até o parque. Considerando as 100 pessoas entrevistadas, $73 \%$ utilizaram o carro como meio de transporte para se deslocar até o parque, uma de ônibus, 11\% foram caminhando, $11 \%$ de carona e $4 \%$ de motocicleta.

Os frequentadores entrevistados percorreram em média uma distância de 10,57 quilômetros por viagem de ida e volta, consumindo um total de 150,2 litros de combustível, gerando um consumo médio de 2,06 litros/ viagem de ida e volta/carro (150,2 litros/73 carros). O preço médio utilizado para o combustível é de R \$1,36/litro, calculado baseando-se no preço atual dos combustíveis, com o álcool a R \$1,28/litro, gasolina a $\mathrm{R} \$ 2,60$ / litro e o óleo diesel a R\$2,36/litro, devidamente ponderados na proporção de $40 \%, 30 \%$ e $3 \%$ respectivamente.

Dentro do universo dos frequentadores entrevistados, 176 entrevistados se deslocaram até o parque utilizando-se de meios automotores, automóveis com diferentes lotações, motocicleta e ônibus.

Quanto ao número de pessoas por automóvel/viagem (com lotações diferentes), 17 dos automóveis observados trafegavam com uma pessoa, 23 com duas pessoas; 26 com três pessoas, cinco com quatro pessoas, e apenas dois dos automóveis observados estavam com cinco pessoas. Para estimativa dos custos de deslocamento ida e volta por pessoa, referentes apenas ao gasto com combustível, ficando de fora gastos com pneus, depreciação do automóvel, foi feita uma média ponderada do número de pessoas transportada por automóvel por viagem por lotação.

Como temos diferentes números de pessoas/automóvel/viagem (lotações), temos também diferentes estimativas de custo médio por pessoa/viagem para se deslocar até ao parque, quanto maior a lotação do automó- 
vel/viagem menor é o custo de deslocamento por pessoa/viagem. Ponderando teremos, para carros com apenas uma pessoa, o custo médio foi de $R \$ 2,81$ / pessoa, para carros com duas $R \$ 1,40$, considerando três $R \$ 0,96 /$ pessoa, para carros com quatro pessoas $\mathrm{R} \$ 0,70$ e $R \$ 0,56 /$ pessoa para carros com lotação de cinco passageiros.

Tabela 3 - Número de pessoas e estimativa do custo de deslocamento, Cuiabá, MT, 2009.

\begin{tabular}{lcc}
\hline Meio de transporte & $\begin{array}{c}\text { Número de } \\
\text { pessoas }\end{array}$ & $\begin{array}{c}\text { Valor } \\
\text { total (R\$) }\end{array}$ \\
\hline Onibus & 01 & 4,60 \\
Motocicleta & 04 & 6,24 \\
Automóvel - Lotação 1 & 17 & 47,77 \\
Automóvel - Lotação 2 & 46 & 64,40 \\
Automóvel - Lotação 3 & 78 & 74,88 \\
Automóvel - Lotação 4 & 20 & 14,00 \\
Automóvel - Lotação 5 & 10 & 5,60 \\
\hline Total & 176 & 217,49 \\
\hline
\end{tabular}

Pela tabela 3, observa-se que, entre os frequentadores entrevistados no parque, quatro pessoas entrevistadas utilizaram a moto sem o carona como meio de transporte para se deslocar até o parque, para essas quatro pessoas obteve-se uma estimativa de custo médio de $R \$ 1,56 /$ pessoa/viagem de ida e volta.

Entre os entrevistados no parque, uma única pessoa que utilizou o ônibus para deslocamento, esta pessoa utilizou-se da linha 308 (Ribeirão do Lipa), gastando assim $\mathrm{R} \$ 4,60$ / pessoa/viagem de ida e volta. De posse dos valores médios ponderados, em que quatro pessoas se deslocam de motocicleta a um custo total de $\mathrm{R} \$ 6,24 ; 01$ pessoa se desloca de ônibus a um custo de $\mathrm{R} \$ 4,60 ; 17$ pessoas em automóveis com lotação de uma pessoa a um custo total de $\mathrm{R} \$ 47,77 ; 46$ pessoas em automóveis com lotação de duas pessoas a $\mathrm{R} \$$ 64,40; 78 pessoas em automóveis com lotação de três pessoas a $\mathrm{R} \$ 74,88 ; 20$ pessoas em automóveis com lotação de quatro a $R \$ 14,00 ; 10$ pessoas em automóveis com lotação de cinco pessoas a um custo total de $\mathrm{R} \$ 5,60$; obtém-se um custo total final de $\mathrm{R} \$ 217,49$.

Esse valor estimado dividido pelo número total de frequentadores entrevistados que se deslocaram por meios automotores
(176) resulta em um valor médio ponderado de $\mathrm{R} \$ 1,21$, ou seja, os valores obtidos pelo Método Custo de Viagem (MCV) mostram que os entrevistados do parque estão dispostos a desembolsar o equivalente a $\mathrm{R} \$ 1,21$ / pessoa/ visita. Esse resultado corrobora com os de Hildebrand et al. (2002) que, em seu trabalho no Bosque Alemão em Curitiba, PR, encontraram Dap (disposição a pagar) $\mathrm{R} \$ 1,21 /$ pessoa/visita ao bosque para manutenção das áreas verdes.

Na média, os entrevistados se deslocam até ao parque utilizando-se de carro próprio transportando mais uma pessoa, percorrendo uma distância média de 11 quilômetros por trajeto, totalizando uma viagem de $22 \mathrm{~km}$ de ida e volta em um tempo médio de 34 minutos por viagem.

O número estimado de pessoas que visitam o parque por final de semana por dia é de 2.226 pessoas/dia (sábados e domingos). Considerando oito dias de finais de semanas por mês e 12 meses por ano teremos 96 dias de finais de semana no ano, logo (96 x 2.226) 213.696 pessoas visitando o parque anualmente aos finais de semana (sábado e domingo). Portanto 213.696 visitantes/ano/ finais de semana $\times \mathrm{R} \$ 1,21 /$ visitante teremos $\mathrm{R} \$ 258.572,16$ é o valor do parque considerando apenas os finais de semana.

Considerando que, em todos os dias do ano, haverá movimento no parque igual aos finais de semana teremos: 365 dias $\times 2.226$ visitantes/dia $\times \mathrm{R} \$ 1,21 /$ pessoa totalizando $\mathrm{R} \$$ 983.112,90/ano como sendo o valor do parque pelo MCV na melhor das hipóteses.

\section{Valoração contingente}

Quando consultados sobre a disposição a pagar pela visita ao parque, $23 \%$ dos frequentadores entrevistados julgaram correta a cobrança pela visita, e $77 \%$ são a favor da entrada franca.

Os resultados da pesquisa mostram que, no que diz respeito à disposição a pagar (DAP) pelo uso do PEMB por visita, 63\% dos entrevistados estão dispostos a pagar um valor entre $R \$ 0,50$ e $R \$ 1,00$ por entrada, $25 \%$ um valor entre $R \$ 1,00$ e $R \$ 3,00,5 \%$ entre $R \$$ 3,00 e $\mathrm{R} \$ 5,00$, e $7 \%$ não estariam dispostos a pagar nada pelo uso do parque. Já no trabalho realizado por Sousa e Mota (2006), no Parque 
Metropolitano de Pituaçu (PMP), em Salvador, BA, o método de avaliação contingente permitiu constatar que $63,4 \%$ dos usuários do PMP estão dispostos a pagar pela manutenção das suas funções, com $R$ \$ 7,72/ mês, ou seja, 0,25733 centavos por dia.

Utilizando o valor $\mathrm{R} \$ 1,00$ que foi o maior obtido revelado pela maioria dos entrevistados (63\%) quanto a sua disposição a pagar (DAP) para entrar no parque para estimativa do valor anual do parque, teremos: para 213.696 pessoas $(96 \times 2.226)$ visitando o parque anualmente aos finais de semana (sábado e domingo), um total estimado de R \$ $213.696,00(\mathrm{R} \$ 1,00 \times 213.696$ pessoas) como o valor do parque pelo Método de Valoração Contingente.

Considerando que, em todos os dias do ano, haverá movimento no parque igual aos dos finais de semana teremos: 365 dias $x$ 2.226 visitantes/dia $\times \mathrm{R} \$ 1,00$ totalizando $\mathrm{R} \$$ $812.490,00 /$ ano como sendo o valor do parque pelo MVC na melhor das hipóteses.

\section{Considerações finais}

Os valores obtidos pelo Método Custo de Viagem mostram que os frequentadores entrevistados no parque têm uma disposição para desembolsar o equivalente a $R \$ 1,21$ / pessoa/visita ao parque.

A disposição média a pagar encontrada para o público entrevistado pelo Método de Valoração Contingente foi de um valor que se situa entre $R \$ 0,50$ e $R \$ 1,00$ por pessoa/ visita ao parque.

Os moradores da região oeste da cidade de Cuiabá foram os mais beneficiados pelos serviços ambientais oferecidos pela criação do Parque Estadual Mãe Bonifácia.

O parque atende todas as faixas etárias, característica que demonstra acerto na estrutura e funcionamento no atendimento ao público de ambos os sexos.

A maioria dos frequentadores são maiores de idade, casados, com renda mensal familiar acima de $\mathrm{R} \$ 1.000,00$, com curso superior completo e na ativa. Eles visitam o parque de maneira esporádica nos finais de semana para fazer caminhada, sentem-se seguros na área do parque, permanecendo de uma a duas horas no período matutino.

\section{Referências}

ABREU, Elaine Aparecida Pereira de; SILVA, Agnaldo Gomes da; SILVA JUNIOR, Gilberto Gomes da. Valoração econômica: aplicação do Método do Custo de Viagem para a Praia da Avenida em Maceió. ENCONTRO NACIONAL DE ECONOMIA, ANPEC, 36., 2008. Disponível em: <http:/ / www.anpec.org.br/encontro2008/ artigos/200807211822360.pdf>. Acesso em: 9 jul. 2012.

ABREU, Eduardo Figueiredo. Aplicação do Método de Valoração Contingente (MVC) para obtenção do valor de uso recreacional do Parque Nacional da Chapada dos GuimarãesPNCG-MT. Projeto de Pesquisa (Mestrado) - Universidade de Brasília, Brasília, 2004.

BABBIE, Earl. Métodos de pesquisas de Survey. Trad. de G. Cezarino. Belo Horizonte: UFMG, 1999. 519p.

BELLIA, Vitor. Introdução à Economia do Meio Ambiente. Brasília: Instituto Brasileiro do Meio Ambiente e dos Recursos Naturais e Renováveis, 1996.

BRASIL. Lei n. 9.985 de 18 de julho de 2000.

CUIABÁ. Lei complementar $n$. 004 de 24 de dezembro de 1992.

CUNHA E MENEZES, Pedro da. Raising the priority of urban areas in protected area systems in Brazil and beyond. In: TRZYNA, T. The Urban Imperative: Urban Outreach Strategies for Protect Areas Agencies. Sacramento: California Institute of Public Affairs. 2005. Disponível em: <http://www.interenvironment.org/ pa/menezes.htm>. Acesso em: 9 jul. 2012.

GIL, Antônio Carlos. Métodos e técnicas de pesquisa social. 5. ed. São Paulo: Atlas, 2007.

HILDEBRAND, Elisabeth; GRAÇA, Luiz Roberto; HOEFLICH, Vitor Afonso. "Valoração contingente" na avaliação econômica de áreas verdes urbanas. Revista Floresta, 32 (1): 121-132, 2002.

KOGA, Érika Sayuri; OLIVEIRA, Anna Carolina Lobo de; OLIVEIRA, Caroline da Silva. Perfil dos visitantes nos parques estaduais de São Paulo: estudo do Programa Trilhas de São Paulo. CONGRESSO NACIONAL DE ECOTURISMO, 8.; ENCONTRO INTERDISCIPLINAR DE ECOTURISMO EM UNIDADES DE CONSERVAÇÃO, 4. Revista Brasileira de Ecoturismo, São Paulo, v. 4, n. 4, p. 554, nov. 2011.

LADEIRA, Alecia Silva; RIBEIRO, Guido Assunção; DIAS, Herly Cardoso Teixeira; SCHAEFER, Carlos Ernesto Gonçalves Reynaud; FERNANDES-FILHO, Elpídio; OLIVEIRA-FILHO, Ary Teixeira. O perfil dos visitantes do Parque Estadual do Ibitipoca, Lima Duarte, MG. Revista Árvore, Viçosa, MG, v. 31, n. 6, p. 1091-1098, 2007.

MALTA, Ricardo Rodrigues; COSTA, Nadja Maria Castilho da. Gestão do uso público em unidade de conservação: a visitação no Parque Nacional da Tijuca - RJ. Revista Brasileira de Ecoturismo, São Paulo, v. 2, n. 3, p. 273-294, set. 2009.

MAY, Peter Herman; LUSTOSA, Maria Cecília Junqueira; DA VINHA, Valéria Gonçalves. Economia do meio ambiente: teoria e prática. Rio de Janeiro: Elsevier, 2003. 318p. 
MAY, Tim. Pesquisa social: questões, métodos e processos. Trad. de C. A. S. N. Soares. 3. ed. Porto Alegre: Artmed, 2004. 288p.

MATO GROSSO. Decreto de n. 1.470 de 9 de junho de 2000.

MOTTA, Ronaldo Seroa. Manual para valoração econômica de recursos ambientais. Brasília: MMA, 1998.

NOGUEIRA, Jorge Madeira; MEDEIROS, Marcelino Antônio Asano de. Valoração econômica do meio ambiente: aspectos teóricos e operacionais. REUNIÃO ANUAL DA SOCIEDADE BRASILEIRA PARA O PROGRESSO DA CIÊNCIA (SBPC), 50., Natal, 1998. Disponível em: <http://www.unb.br/face/eco/jmn/publicacoes/1 0ValoracaoEconomica.pdf>. Acesso em: 10 jul. 2012.

ROMEIRO, Ademar Ribeiro; REYDON, Bastiaan; LEONARDI, Maria Lúcia Azevedo. Economia do meio ambiente: teoria, políticas e a gestão de espaços regionais. Campinas, SP: UNICAMP/EMBRAPA/FAPESP, 1996.

SILVA, Mônica Lima da; SANCHES, Vitor Quadros Altomare; CIESLAK, Silvia Roberta. Perfil etário, nível de escolaridade e percepção ambiental dos visitantes do Parque Municipal Chico Mendes, Ouro Preto D'Oeste, Rondônia. CONGRESSO DE NATUREZA, TURISMO ESUSTENTABILIDADE - CONATUS, 1., Bonito, MS, 2010.

SOUSA, Geneci Braz de; MOTA, José Aroudo. Valoração econômica de áreas de recreação: o caso do parque metropolitano de Pituaçu, Salvador, BA. Revista de
Economia, Curitiba, v. 32, n. 1 (ano 30), p. 37-55, jan./ jun. 2006.

SOUZA, Paula Cristina de; MARTOS, Henry Lesjak. Estudo do uso público e análise ambiental das trilhas em uma unidade de conservação de uso sustentável: floresta nacional de Ipanema, Iperó-SP. Revista Árvore, Viçosa, MG, v. 32, n. 1, p. 91-100, 2008.

SOUZA, Paulo Cezar Alves de. Funções sociais e ambientais de parque urbano instituído como unidade de conservação: percepção dos usuários do parque natural municipal Barigui em Curitiba, Paraná. 2010. Dissertação (Mestrado em Gestão Urbana) - Programa de Pós-Graduação Em Gestão Urbana, Pontifícia Universidade Católica do Paraná - PUCPR, Curitiba, 2010.

SOUZA, Roberta Fernanda da Paz. Economia do meio ambiente e responsabilidade social: os métodos de valoração econômica e controle ambiental. CONGRESSO DA SOBER “CONHECIMENTOS PARA AGRICULTURA DO FUTURO", 45., Universidade Estadual de Londrina, PR, 2007. Disponível em: <http:/ / www.sober.org.br/ palestra/6/1128.pdf>. Acesso em: 5 jun. 2012.

VILANOVA, Silvia Regina Fernandes. Composição florística e valorização econômica de uma Unidade de Conservação Urbana. Dissertação (Mestrado em Ciências Florestais e Ambientais) - Universidade Federal de Mato Grosso, Cuiabá, MT, 2008. Disponível em: <http:/ / www.ufmt. br/fenf/arquivos/24e6c7a6dafccee94326ced4ba6b884b. pdf>. Acesso em: 9 jun. 2012. 